\title{
<AT>Hospital Nutrition Assessment Practice 2016 Survey
}

\section{(1)}

<AU>Kris M. Mogensen, MS, RD-AP, LDN, CNSC ${ }^{1}$; Sandra Bouma, MS, RDN, $\mathrm{CSP}^{2}$; Amanda Haney, MS, RD, CNSC ${ }^{3}$; Vincent W. Vanek, MD, FACS, FASPEN ${ }^{4}$; Ainsley Malone, MS, RD, LD, CNSC, FAND, FASPEN ${ }^{5}$; Sadeg A. Quraishi, MD, MHA, MMSc ${ }^{6}$; and Peggi Guenter, PhD, RN, FAAN, FASPEN ${ }^{7}$

From the 'Department of Nutrition, Brigham and Women's Hospital, Boston, Massachusetts; ${ }^{2}$ Pediatric Cystic Fibrosis and Gastrointestinal Clinics, C.S. Mott Children's Hospital, University of Michigan Health System Michigan Medicine, Ann Arbor, Michigan; ${ }^{3}$ Miller Children's and Women's Hospital Long Beach, Long Beach, California; Mercy Health Youngstown Region, St. Elizabeth Youngstown Hospital, Youngstown, Ohio; Mt. Carmel West Hospital, Columbus, Ohio; ${ }^{6}$ Harvard Medical School and Massachusetts General Hospital, Boston, Massachusetts; and the ${ }^{7}$ Clinical Practice, Quality, and Advocacy, American Society for Parenteral and Enteral Nutrition, Silver Spring, Maryland.

Financial disclosures: None declared.

Conflicts of interest: K.M. Mogensen is a member of ThriveRx Nutrition Advisory Board, and speaker for Baxter International Conference for Advancing Nutrition; $\mathrm{S}$. Bouma is a speaker for Abbott Nutrition Health Institute; S.A. Quraishi is a consultant for Abbott Nutrition.

\section{$<$ CA>Corresponding Author:}

Ainsley Malone, MS, RD, 1356 Windtree Court, New Albany, Ohio 43054.

Email: ainsleym@nutritioncare.org

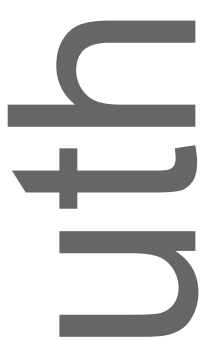

This is the ant manuscript accepted for publication and has undergone full peer review but has not been thi wo tl c copyediting, typesetting, pagination and proofreading process, which may lead to differences betw this version and the Version of Record. Please cite this article as doi:

10.1002/ncp.10179. 
$<A B>A b s t r a c t$

Background: Malnutrition is a significant problem for hospitalized patients in the United States. Nutrition assessment is an important step in recognizing malnutrition; however, it is not always performed using consistent parameters. Methods: A survey among U.S. American Society for Parenteral and Enteral Nutrition (ASPEN) members was conducted to collect data on nutrition assessment parameters used in hospitals and to establish how facilities use their electronic health record (EHR) to permit data retrieval and outcome reporting. Results: The survey was developed by the ASPEN Malnutrition Committee and was sent to 5487 U.S. ASPEN members, with 489 responding for a $9 \%$ response rate. Ninetyeight percent of adult and $93 \%$ of pediatric respondents indicated a registered dietitian completed the nutrition assessment following a positive nutrition screen. Variables most frequently usedamong adult respondents included usual body weight, ideal body weight, and body mass index. Among pediatric respondents, weight-for-age and height-for-age percentiles and length/height-for-age percentile were most frequently used. Both adult and pediatric respondents indicated use of physical assessment parameters, including muscle and fat loss and skin assessment. Eighty-seven percent of adult and $77 \%$ of pediatric respondents indicated they are using the Academy of Nutrition and Dietetics (Academy) and ASPEN Consensus Malnutrition Characteristics for Adult and Pediatric Malnutrition, respectively Qverall, $97 \%$ of respondents indicated nutrition assessment documentation was completed via an EHR. Of all respondents, $61 \%$ indicated lack of clinical decision support within their EHR. Conclusion: This survey demonstrated significant use of the Academy/ASPEN malnutrition consensus characteristics. (Nutr Clin Pract. 2018;xx:xxx-xxx)

\section{$<\mathrm{H} 1>$ Introduction}

Malnutrition is a significant problem among hospitalized patients in the United States. It is associated with poor outcomes, high costs, and readmissions. ${ }^{1-3}$ Although assessment of nutritional status is an important step in recognizing malnutrition, it is not universally performed in patients admitted to U.S. hospitals. Even patients who may be screened and identified as being at risk for malnutrition do not always undergo full nutrition assessment. ${ }^{4}$ Moreover, the consistency of parameters and biomarkers used to assess nutritional status varies across institutions. ${ }^{4}$

In 2012, American Society for Parenteral and Enteral Nutrition (ASPEN) conducted a survey on nutrition care processes used in hospitals to evaluate nutrition screening and assessment processes in adult and pediatric patients. The survey also sought to assess the

This article is protected by copyright. All rights reserved. 
use of the (then) recently published Academy of Nutrition and Dietetics (Academy) and ASPEN Malnutrition Adult Consensus Characteristics. ${ }^{4,5}$ Additionally, in 2015, the Pediatric Consensusstatement of the Academy/ASPEN was published outlining the indicators recommended for the identification and documentation of pediatric malnutrition (undernutrition). ${ }^{6}$ The pediatric nutrition assessment is based on a different framework compared with adult nutrition assessment and includes variables specific to the pediatric population

Therefore, the current survey's primary aim was to assess parameters currently being used by adult and pediatric practitioners for the diagnosis of malnutrition and to make comparisons with the 2012 survey. This survey was designed to determine what approaches to nutritionassessment are used across the country in all age populations. The secondary aim was to determine how nutritional assessment data are being documented and retrieved from electronic health records (EHRs). The results are intended to enhance ASPEN's malnutrition education efforts and to provide a basis for future malnutrition research opportunities using an EHR framework.

$<$ H1 $>$ Methods

$<$ H2>Survey Methodology

The final list of questions used in the survey (full survey available in Supplementary material) was generated by the ASPEN Malnutrition Committee and was based on a previous survey conducted by the Committee. ${ }^{4}$ In addition to obtaining demographic information, survey questions addressed who performs nutrition assessments and which variables are being used (respondents were asked to select all those that apply). Respondents were also asked if they were using the Academy/ASPEN malnutrition consensus composite characteristics. ${ }^{5,6}$ In addition, questions about how nutrition assessment data can be retrieved via the EHR were included. There were no mandatory questions and respondents could skip questions if desired. Following completion of demographic questions, respondents were directed to either adult-specific or pediatricspecific questions for the remainder of the survey. Questions were not weighted because the intent was to capture information reflective of the respondents' practices. Content validity of the study instrument was assessed by the ASPEN Clinical Practice Committee and selected content experts. A commercially available, internet-based, electronic tool was then used to construct the survey (Survey Monkey, San Mateo, CA). Emailed invitations with a link to the survey went to all ASPEN members who had active membership in the October 2016 membership database, were identified as U.S. residents, and provided a current email

This article is protected by copyright. All rights reserved. 
address. They were instructed to complete the survey only if they worked in a hospital setting. Responses were limited to 1 per email address. The survey was limited to U.S. hospital employees to facilitate potential diagnostic validation research using U.S. EHR systems.

Survex participation was voluntary, free of charge, and no remuneration was provided to respondents. The survey was open from November 18, 2016 to December 17, 2016; in addition to the initial invitation, 2 additional email reminders were sent to the study cohort. Data from all surveys were included, were aggregated for reporting purposes, and were analyzed using descriptive statistics. Free text-box information was not categorized or coded in any manner but was summarized by frequency of response. Because the survey was anonymous and delivered via a web-based program, and potential respondents could easily decline to accept the invitation to participate, there was no procedure or intervention involved. Informed consent was assumed by participation and completion of the survey. The study proposal was approved and granted exempt status by the Partners Human Research Committee (Institutional Review Board).

$<$ H1 $>$ Results

$<H 2>$ General Overview

The survey was sent to 5487 ASPEN members based in the U.S., and 489 individuals who worked in hospitals responded and completed the survey ( $9 \%$ response rate). Survey response by discipline was $90 \%(n=439)$ dietitians, $6 \%(n=30)$ pharmacists, $2 \%(n=12)$ physicians, and $2 \%(n=7)$ either nurses, nurse practitioners, or physician assistants combined. In terms of practice environment, $45 \%(n=217)$ of survey respondents provided care primarily in academic medical centers, $46 \%(n=224)$ in community hospitals, $3 \%(n=$ $16)$ in the Veteran's Health Administration or military hospitals, and $6 \%(n=24)$ in other types of facilities (consisting largely of individuals who provided care in long-term acute care hospitals). The size of the hospitals in which the study participants practiced included: $<100$ beds $(13 \% ; n=63) ; 100-250$ beds $(26 \% ; n=128) ; 251-500$ beds $(34 \% ; n=162) ;$ and $>500$ beds $(27 \% ; n=131)$.

$<$ H2>Natrition Assessment Parameters

Of the 489 survey respondents, 423 (87\%) identified themselves as working primarily with adult patients, while 64 (13\%) work primarily with pediatric patients ( 2 skipped this question). When the respondents were asked, "Once a patient is screened, who completes the nutrition assessment at your hospital," 89\% (357 adult and 51 pediatric) who answered

This article is protected by copyright. All rights reserved. 
the question indicated that a registered dietitian (RD) typically completed the assessment and 11\% (58 adult and 4 pediatric) indicated that physicians, diet technicians, nurses, or pharmacists completed the nutrition assessment. Respondents checked all that applied. Table 1 presents the responses to the questions about which variables are used for the adult and pediatric patient nutrition assessment.

\section{$<$ H2>Parameters Not Collected}

Respondents were asked about additional data that they would like to collect that was not currently being collected. Answers included: 1) hand grip strength, 2) indirect calorimetry, 3) triceps skinfold thickness, and 4) nutrition-focused physical exams. In addition, many responders indicated that they would like to collect data using more direct measures of body composition, including bioelectric impedance analysis, computerized tomography, dual-energy x-ray absorptiometry, and/or ultrasound.

$<$ H2>Use of Academy/ASPEN Characteristics and Markers Instruments

Of the 413 survey respondents who answered the specific question, 353 (85\%) indicated they were currently using the Academy/ASPEN consensus malnutrition indicators for nutrition assessment ( $87 \%$ of adult respondents [312 of 360 ] and $77 \%$ of pediatric respondents [41 of 53]). Respondents who were using the consensus indicators were using parameters as outlined in Table 2.

When respondents who reported not using the Academy/ASPEN malnutrition characteristics were asked what assessment tools they used, the majority indicated using their own "in-house" tool (53\%; 51 adult and 11 pediatric). Of the remaining responses, 23\% (16 adult and 4 pediatric) reported using a variety of other instruments, some of which are not considered nutrition assessment tools.

$<$ H2>Electronic Health Record

An EHR was used to document the nutrition assessment for the vast majority of respondents who reported their data can be entered into an EHR using free text or structured data, eg, discrete data using either drop-down lists, buttons to click on, or boxes to check. Most of the respondents documenting within an EHR entered the nutrition assessment data either completely $(12 \%$ [ $n=390]$ of respondents) or partially $(67 \%$ of respondents) as structured data. Despite this high percentage of nutrition assessment data being entered discretely, only $44 \%$ of respondents reported that their hospital could run reports that automatically extract nutrition assessment data from the EHR. Only $24 \%$ of respondents reported that their EHR provided clinical decision support, meaning that when

This article is protected by copyright. All rights reserved. 
the patient meets criteria for malnutrition the provider is prompted to document malnutrition in their notes (Table 3).

\section{$<$ H1 $>$ Discussion}

This survey was gonducted to assess malnutrition diagnostic parameters being used by adult and pediatric practitioners and to determine how nutritional assessment data aare being documented and retrieved from EHRs. It is a follow-up to the 2012 nutrition assessment and screening survey which was sent not only to ASPEN members but also to members of the Academy ofMedical-Surgical Nurses and the Society of Hospital Medicine, yielding a larger number of responses (1777 total responses). The current survey was limited to U.S. ASPEN members as a prelude to conducting important validation research using the U.S. healthcare EHR framework. The response rate was similar to another recent survey of ASPEN membership and the rate reported in the literature for survey-based research (within reported ranges for members of an organization). ${ }^{8}$ Typical range of reported response rates are $5 \%-40 \%$ for eustomers or members of an organization. ${ }^{7,8}$ One study found that email surveys had a lower response rate than paper surveys, but they also found that follow-up reminders had a significant effect on response rate, which was employed for this survey. ${ }^{9}$

This survey was answered by RD members at a higher proportion than the RD ASPEN membership (ASPEN Internal Membership Database) (90\% response rate vs $68 \%$ of membership). This was much higher than the prior survey (62\% RD response rate) but should be expected given that the prior survey was sent to 3 societies rather than being restricted to U.S. ASPEN members. ${ }^{4}$ As with the prior survey, the RD was identified as the clinician primarily responsible for conducting the nutrition assessment ${ }^{4}$; however, $11 \%$ of the respondents reported that physicians, nurses, pharmacists, or nutrition and dietetic technicians registered (NDTR) conduct the nutrition assessment. For ASPEN members, this would be consistent with practice standards for nutrition support physicians, nurses, and pharmacists. ${ }^{10-13}$ The role of the NDTR in conducting full nutrition assessments should be explored further to assure that the NDTR is practicing within the appropriate Standards of Practice/Standards of Professional Performance as published by the Academy of Nutrition and Dietetics. ${ }^{14}$

The current survey asked more detailed questions about the components of nutrition assessment compared with the 2012 survey. In general, anthropometric measurements (height, weight, weight change, head circumference, and interpretation of pediatric growth measures) are used by most practitioners as part of the nutrition assessment process. It is difficult to evaluate each parameter and compare it with the 2012 survey since most of the

This article is protected by copyright. All rights reserved. 
anthropometric measurements were evaluated in aggregate, rather than individually as they are in the current survey. Use of physical examination components have increased dramatically compared with 2012. For example, in 2012, only $33 \%$ of adult practitioners and $50 \%$ of pediatric practitioners were conducting physical examinations for vitamin or traceelement deficiencies. In the current survey, $78 \%$ of adult practitioners and $71 \%$ of pediatric practitioners are conducting skin assessments (this includes evaluation for vitamin/mineral deficiencies, pressure injuries, and wound healing). This points to a greater emphasis of conducting nutrition-focused physical examinations in both adult and pediatric patients and is consistent with results identified from other surveys. ${ }^{15,16}$

Clinicians continue to use circulating proteins as part of the nutrition assessment process, although this use seems to be declining. In the 2012 survey, approximately $63 \%$ of adult practitioners and $46 \%$ of pediatric practitioners reported using serum proteins as part of the assessment process, whereas in the current survey, $29 \%$ of adult practitioners and $38 \%$ of pediatric practitioners reported using albumin in nutrition assessment. This seems to suggest a movement away from using circulating proteins as part of the nutrition assessment since they are significantly influenced by inflammation and are unreliable measures of nutrition status. ${ }^{17}$ What is unclear is how these proteins are being used as part of the assessment process. The use of C-reactive protein may be beneficial in identifying the degree of inflammation (which is helpful for identifying the context of malnutrition); it can be hypothesized that the use of albumin or prealbumin in the assessment process makes them surrogates for measures of degree of inflammation, ${ }^{18}$ but additional questioning within the survey would have been necessary to elucidate this conclusion.

A major new finding of this survey is characterizing the use of the Academy/ASPEN malnutrition characteristics for adult and pediatric patients. In the 2012 nutrition screening and assessment survey, the adult malnutrition characteristics paper had been published only 6 months prior to survey administration, and the pediatric malnutrition characteristics 6 were not yet published. At that time, $67 \%$ of dietitians and only $9 \%$ of the nurses who responded to the survey were aware of the publication, demonstrating a significant educational opportunity. In the current survey, $85 \%$ of the respondents (adult and pediatric) identified use of the malnutrition diagnostic characteristics in their patients. This is consistent with a recently published survey by Dietitians in Nutrition Support, a practice group of the Academy in which $94 \%$ of adult and pediatric respondents identified use of the Academy/ASPEN malnutrition characteristics for diagnosing malnutrition. ${ }^{14}$ In the current survey, with adult practitioners, there was high utilization (>80\%) of 5 of the 6 adult characteristics; only $22 \%$ of respondents used diminished hand grip strength (HGS)

This article is protected by copyright. All rights reserved. 
consistently. This is a dramatic reduction from the 2012 survey where almost $95 \%$ of adult practitioners reported using HGS as part of the assessment process. It is unclear why there was such a dramatic drop in the use of this parameter, and it suggests that there are new barriers that may limit the use of this assessment tool. Additional research is required to explore this problem. There are 8 characteristics that can be used to identify pediatric malnutrition. Six of the 8 are used by $\geq 85 \%$ of practitioners. Two characteristics are used less frequently, with $78 \%$ evaluating deceleration in weight for length ( $<2$ years old) or BMI ( $\geq 2$ years old) and only $50 \%$ using mid-upper-arm circumference $z$-score. As with HGS in adults, barriers for evaluation of these 2 characteristics need to be explored and alternatives may be proposed.

Adult clinicians not using the Academy/ASPEN adult malnutrition characteristics use a variety of tools to determine the presence of malnutrition. Some use validated tools, such as Subjective GlobatAssessment or the Mini Nutrition Assessment. Some clinicians are using their own home-grown tool to determine presence of malnutrition, and others are using screening tools as part of the nutrition assessment process. In pediatrics, clinicians not using the Academy/ASPEN pediatric malnutrition characteristics are using World Health Organization criteria or the Subjective Global Nutrition Assessment for children. As with adult practitioners, some are using their own tool. It is difficult to determine the true prevalence of malnutrition in both adult and pediatric patients if practitioners are not using consistent diagnostic criteria. Important areas of research would be to determine why clinicians select the tools that they use, how they developed the home-grown tools, and what the perceived barriers are to using the Academy/ASPEN clinical characteristics.

The adult and pediatric malnutrition characteristics require validation to assure these clinical characteristics truly predict risk of adverse events known to be tied to malnutrition, including infectious complications, hospital and intensive care unit length of stay, readmission rates after discharge, and mortality. ${ }^{19}$ This will require access to nutrition assessment data and outcomes reporting from many institutions and settings to allow for robust data analysis. Easy access to nutrition assessment data and outcome measures is an essential part of this process. In this survey, $97 \%$ of the respondents reported use of an EHR in some way ( $86 \%$ fully electronic and $11 \%$ a blend of electronic and paper documentation), which is an increase from a 2014 ASPEN survey where $90 \%-94 \%$ of clinicians used an EHR. ${ }^{20}$ Retrieving relevant documentation to validate the Academy/ASPEN malnutrition characteristics may be challenging due to the way clinical data are documented. Only $12 \%$ have fully structured documentation, with $67 \%$ a mix of structured and free-text documentation and $18 \%$ fully free text. In addition, only $44 \%$ are sure that their nutrition

This article is protected by copyright. All rights reserved. 
assessment data can be extracted from their EHR. Validation efforts will require extraction of both malnutrition data as well as clinical outcomes; clinicians interested in working on validation efforts will need to engage their facility's EHR leadership to move to structured documentation, to determine what nutrition parameters can be extracted from the EHR, and to determine if relevant clinical outcomes data can also be extracted.

\section{Limitations}

This survey has a number of limitations. First, the low response rate may not capture the full experience of U.S. ASPEN members, thereby limiting the ability to generalize results across the U.S. Our survey window was only open for approximately 4 weeks and was close to the November/December holiday season which may have limited available free time for ASPEN members to complete this survey. Moreover, the amount of missing data, as reflected in specific questions and their respondent samples, may have been significant enough to further limit the generalizability of the results. In addition, more than 1 respondent per institution could not be eliminated which may have limited our overall findings. Our low number of pediatric respondents is also a significant limitation. The responses of only 45 pediatric practitioners can give only a very small snapshot of pediatric nutrition assessment practices in the U.S. However, this survey does generate some interesting questions for further research and additional surveying of the ASPEN membership, perhaps with the opportunity for more follow-up questions and free text to allow for explanations and to further characterize nutrition assessment practices in the U.S.

\section{$<\mathrm{H} 1>$ Conclusions}

This survey extends the information gleaned from the 2012 ASPEN nutrition screening and assessment survey. A majority of adult and pediatric clinicians are using the Academy/ASPEN malnutrition diagnostic characteristics, which may allow for multicenter validation studies. Most institutions are using EHRs, but those using a mix of structured and free-text data may have difficulty retrieving relevant nutrition data to participate in validation efforts. Overall, it is encouraging that there is potential for many institutions to participate in these efforts. The survey results provide information for further educational opportunities including use of the Academy/ASPEN malnutrition characteristics as well as

further exploration of visceral proteins and their continued use in the nutrition assessment process. ASPEN will continue to advocate for early screening, assessment, diagnosis, and treatment of malnutrition to decrease morbidity and mortality and improve the quality of life for patients

This article is protected by copyright. All rights reserved. 


\section{Statement of Authorship}

K.M. Mogensen, S. Bouma, A. Haney, V.W. Vanek, A. Malone, S. Quraishi, and P. Guenter contributed to the conception and design of the research; K.M. Mogensen, S. Bouma, A. Haney, V.W.Vanek, A. Malone, S. Quraishi, and P. Guenter contributed to the acquisition and analysis of the data; K.M. Mogensen, S. Bouma, A. Haney, V.W. Vanek, A. Malone, and P. Guenter contributed to the interpretation of the data; and K.M. Mogensen, S. Bouma, A. Haney, V.W. Vanek, A. Malone, and P. Guenter drafted the manuscript. All authors critically revised the manuscript, agree to be fully accountable for ensuring the integrity and accuracy of the work, and read and approved the final manuscript

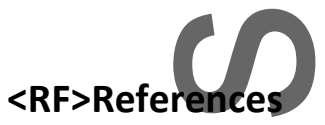

1. Guenter P, Jensen G, Patel V, et al. Addressing disease-related malnutrition in hospitalized patients: a call for a national goal. Joint Comm J Qual Pt Safety. $2015 ; 41: 469-473$.

2. Weiss AJ, Fingar KR, Barrett ML, Guenter P, Hise MH. Characteristics of hospital stays involving malnutrition 2013. XXXXXX: Agency of Healthcare Research and Quality, Statistical Brief \#210; September 2016.

3. Fingar KR, Weiss AJ, Barrett ML, Guenter $\mathrm{P}$, Hise MH. All-cause readmissions following hospital stays for patients with malnutrition, 2013. XXXXXX: Agency of Healthcare Research and Quality, Statistical Brief \#218; December 2016.

4. Patel $\mathrm{V}$, Romano $\mathrm{M}$, Corkins $\mathrm{MR}$, et al. Nutrition screening and assessment in hospitalized patients: a survey of current practice in the United States. Nutr Clin Pract. 2014;29:483-490.

This article is protected by copyright. All rights reserved. 
5. White JV, Guenter P, Jensen GL, et al. Consensus statement: Academy of Nutrition and Dietetics and American Society for Parenteral and Enteral Nutrition: characteristics recommended for the identification and documentation of adult malnutrition (under-nutrition). JPEN J Parent Enteral Nutr. 2012;36:275-283.

-

6. Becker P, Carney LN, Corkins MR, et al. Consensus statement of the Academy of Nutrition and Dietetics/American Society for Parenteral and Enteral Nutrition: indicators recommended for the identification and documentation of pediatric malnutrition (undernutrition). Nutr Clin Pract. 2015;30:147-161.

7. Christensen ML, Ayers P, Boullata JI, et al. Lipid injectable emulsion survey with gap analysis. Nutr Clin Pract. 2017;32:694-702.

8. Ray A. Typical response rates.

http://practicalsurveys.com/respondents/typicalresponserates.php. Published March 20,2006; updated March 12, 2015. Accessed September 22, 2017.

9. Shih $\mathrm{TH}$, Fan X. Comparing response rates in e-mail and paper surveys: a metaanalysis. Educ Res Rev. 2009;4:26-40.

10. Brantley SL, Russell MK, Mogensen KM, et al. American Society for Parenteral and Enteral Nutrition and Academy of Nutrition and Dietetics revised 2014 standards of practice and standards of professional performance for registered dietitian nutritionists (competent, proficient, and expert) in nutrition support. Nutr Clin Pract. 2014;29:792-828.

This article is protected by copyright. All rights reserved. 
11. Mascarenhas MR, August DA, DeLegge MH, et al. Standards of practice for nutrition support physicians. Nutr Clin Pract. 2012;27:295-299. (1)

12. Tucker A, Ybarra J, Bingham A, et al. American Society for Parenteral and Enteral Nutrition (A.S.P.E.N.) standards of practice for nutrition support pharmacists. Nutr Clin Pract. 2015;30:139-146.

13. DiMaria-Ghalili RA, Gilbert K, Lord L, et al. Standards of nutrition care practice and professional performance for nutrition support and generalist nurses. 2015;31:527-547.

14. Academy of Nutrition and Dietetics: Revised 2017 standards of practice in nutrition care and standards of professional performance for nutrition and dietetics technicians, registered. J Acad Nutr Diet. 2018;118:317-326.

15. Dobak S, Peterson S, Corrigan M, Lefton J. Current practices and perceived barriers to diagnosing, documenting, and coding for malnutrition: a survey of the Dietitians in Nutrition Support dietetic practice group. J Acad Nutr Diet. http://dx.doi.org/10.1016/j.jand.2017.03.006.

16. Desjardins S, Brody R, Marcus A, Touger-Decker R. Nutrition focused physical examination practices of registered dietitian nutritionists that have completed an inperson nutrition focused physical examination course. J Acad Nutr Diet. 2016;116:A97.

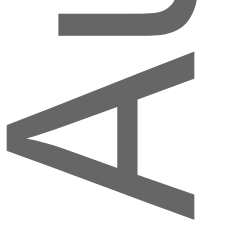

This article is protected by copyright. All rights reserved. 
17. Jensen GL, Bistrian B, Roubenoff R, Heimburger DC. Malnutrition syndromes: a conundrum vs continuum. JPEN J Parenter Enteral Nutr. 2009;33:710-716. conun

18. Jensen GL, Hsiao PY, Wheeler D. Adult nutrition assessment tutorial. JPEN J Parenter Enteral Nutr. 2012;36:267-274.

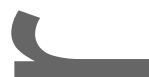

19. Hand R,Murphy W, Field LB, et. Al. Validation of the Academy/A.S.P.E.N. malnutrition clinical characteristics. J Acad Nutr Diet. 2016;116:856-854.

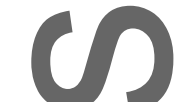

20. Vanek VW, Ayers $P$, Kraft M, et al. Follow-up survey on functionality of nutrition documentation and ordering nutrition therapy in currently available electronic health record (EHR) systems. Nutr Clin Pract. 2016;31:401-415.

Table 1. Individual Variables Used for Nutrition Assessment in Adult and Pediatric Patients.

\begin{tabular}{|c|c|c|}
\hline Variable & $\begin{array}{l}\text { Adult Clinician } \\
\text { Responses } \\
\mathrm{n}=301\end{array}$ & $\begin{array}{l}\text { Pediatric } \\
\text { Clinician } \\
\text { Responses } \\
\mathrm{n}=45\end{array}$ \\
\hline Weight-for-age percentile & $\mathrm{n} / \mathrm{a}$ & $96 \%$ \\
\hline Height-for-age percentile & $\mathrm{n} / \mathrm{a}$ & $96 \%$ \\
\hline Usual body weight & $94 \%$ & $\mathrm{n} / \mathrm{a}$ \\
\hline
\end{tabular}

This article is protected by copyright. All rights reserved. 


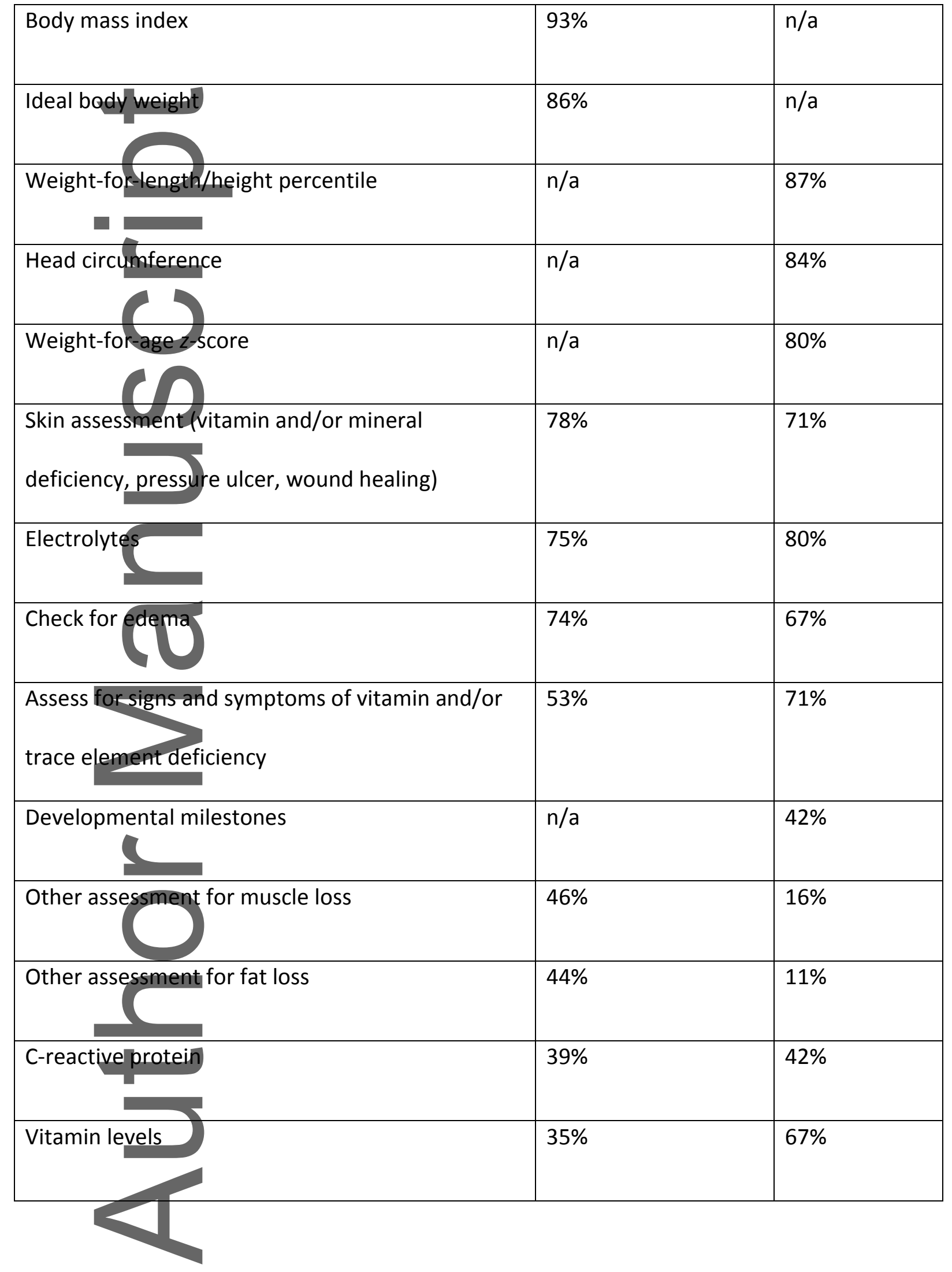

This article is protected by copyright. All rights reserved. 


\begin{tabular}{|c|c|c|}
\hline Activities of daily living & $32 \%$ & $24 \%$ \\
\hline Prealbumin & $31 \%$ & $29 \%$ \\
\hline Albumin & $29 \%$ & $38 \%$ \\
\hline Trace element levels & $26 \%$ & $44 \%$ \\
\hline Hand grip & $13 \%$ & $9 \%$ \\
\hline Other (please specify in text box below) & $8 \%$ & $\mathrm{n} / \mathrm{a}$ \\
\hline Triceps skinfold thickness & $5 \%$ & $11 \%$ \\
\hline Walking a & $4 \%$ & $13 \%$ \\
\hline uscle circumference & $3 \%$ & $56 \%$ \\
\hline dance analysis & $2 \%$ & $0 \%$ \\
\hline sraphy-guided muscle mass & $2 \%$ & $2 \%$ \\
\hline Ultrasou & $1 \%$ & $\mathrm{n} / \mathrm{a}$ \\
\hline Timed chair stand & $<1 \%$ & $\mathrm{n} / \mathrm{a}$ \\
\hline Dual x-ray absorptiometry & $0 \%$ & $9 \%$ \\
\hline
\end{tabular}

This article is protected by copyright. All rights reserved. 
Table 2. Percent Use of Academy/ASPEN Malnutrition Characteristics.

\begin{tabular}{|c|c|}
\hline Adult Characteristics & $\begin{array}{l}\text { Percent of Adult Clinician } \\
\text { Respondents Who Use This } \\
\text { Marker, } \mathrm{n}=312\end{array}$ \\
\hline Inadequate intake & $99 \%$ \\
\hline Weight I & $99 \%$ \\
\hline Evidence of subcutaneous fat loss & $88 \%$ \\
\hline Evidence of muscle loss & $90 \%$ \\
\hline Fluid accumulation & $84 \%$ \\
\hline Diminished hand grip strength & $22 \%$ \\
\hline Pediatric Characte & $\begin{array}{l}\text { Percent of Pediatric Clinician } \\
\text { Respondents Who Use this } \\
\text { Marker, } \mathrm{n}=41\end{array}$ \\
\hline Height-for-age $z$-score & $90 \%$ \\
\hline Weight-for-tength $z$-score & $90 \%$ \\
\hline Body mass index (BMI) z-score & $95 \%$ \\
\hline Mid-upper-arm circumference $z$-score & $60 \%$ \\
\hline
\end{tabular}

This article is protected by copyright. All rights reserved. 


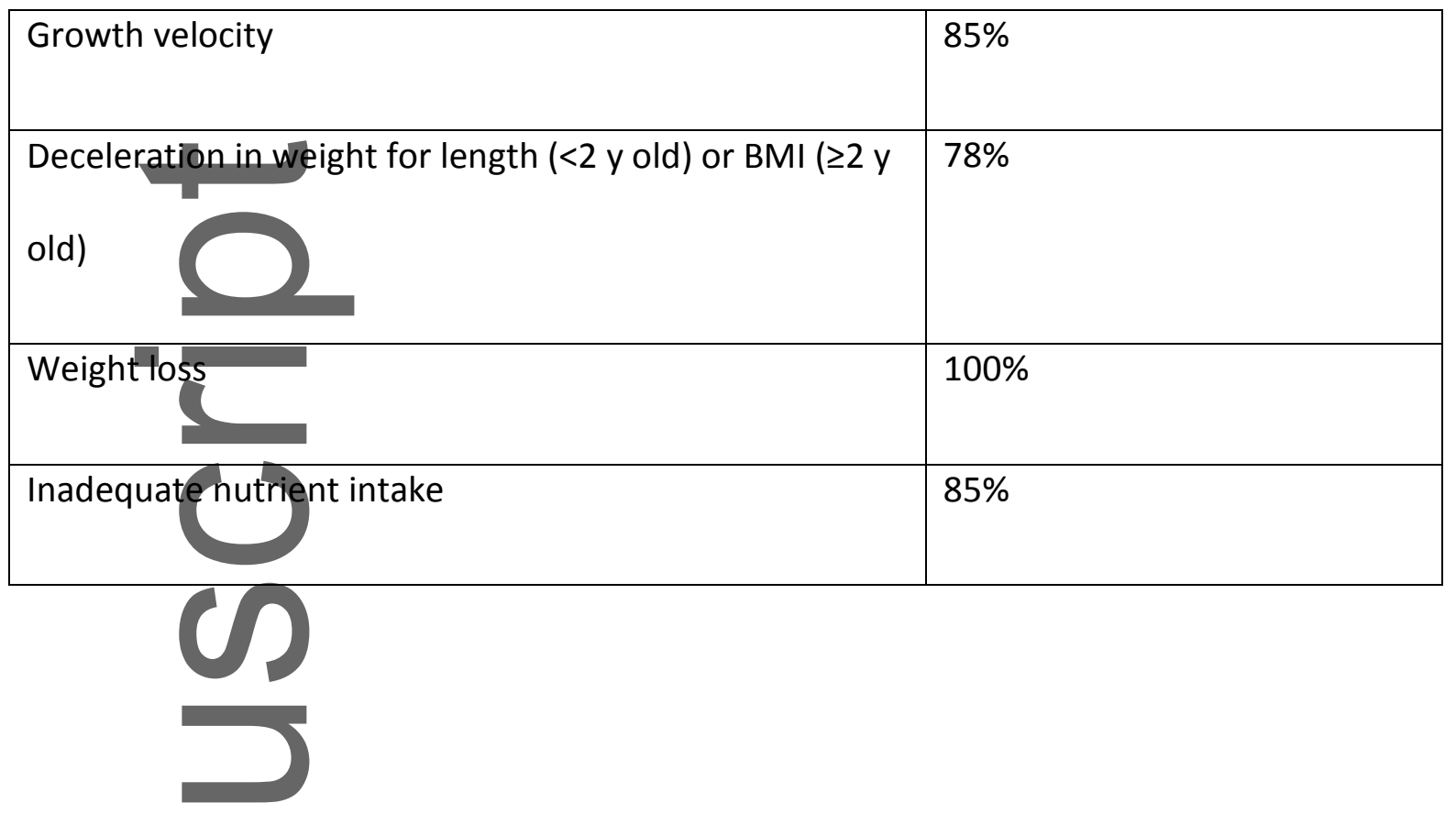

Table 3. Documenting Nutrition Assessment in the Medical Record

\begin{tabular}{|l|c|}
\hline \multicolumn{1}{|c|}{ Type of Medical Record Used } & Percent Respondents, $\mathrm{n}=396$ \\
\hline Electronic & $86 \%$ \\
\hline Paper & $3 \%$ \\
\hline Combination & $11 \%$ \\
\hline Nutrition Assessment Data Format in & Percent Respondents, $\mathrm{n}=387$ \\
\hline EHR & \\
\hline Structured & \\
\hline
\end{tabular}

This article is protected by copyright. All rights reserved. 


\begin{tabular}{|l|c|}
\hline Free text & $18 \%$ \\
\hline I don't know & $3 \%$ \\
\hline CDS for Malnutrition Documentation & Percent Respondents, $\mathrm{n}=387$ \\
\hline No & \\
\hline Yes & \\
\hline I don't know & $24 \%$ \\
\hline Nutrition Assessment Data Extractable & $15 \%$ \\
\hline Yes & Percent Respondents, $\mathrm{n}=384$ \\
\hline
\end{tabular}

EHR, electronic health record; CDS, clinical decision support.

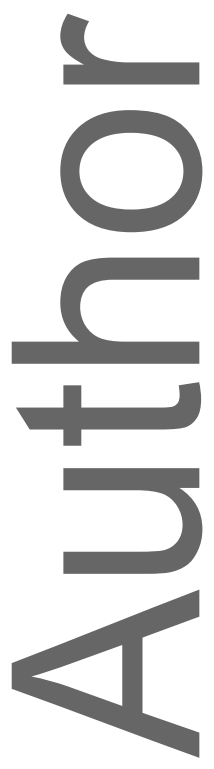

This article is protected by copyright. All rights reserved. 